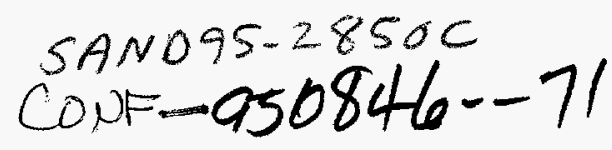

\title{
QUARTZ GAUGE RESPONSE IN ION RADIATION
}

\author{
P.E. Taylor ${ }^{*}$, P.H. Gilbert ${ }^{*}$, C. Kernthaler", L.M. Lee ${ }^{* *}$, \\ E.A. Smith ${ }^{* *}$, S.T. Reeder ${ }^{* *}$, M. U. Anderson ${ }^{* * *}$ \\ *Atomic Weapons Establishment, Aldermaston, Reading, Berkshire, UK, RG7 4PR \\ ** Ktech Corporation, 901 Pennsylvania NE, Albuquerque, NM 87110 \\ *** Sandia National Laboratories, P. O. Box 5800, Albuquerque, NM 87185
}

\author{
RECFIVED \\ DEC 271995 \\ OS.TI
}

This paper describes recent work to make high quality quartz gauge (temporal and spatial) shock wave measurements in a pulsed ion beam environment. Intense ion beam radiation, nominally $1 \mathrm{MeV}$ protons, was deposited into material samples instrumented with shunted quartz gauges adjacent to the ion deposition zone. Fluence levels were chosen to excite three fundamentally different material response modes (1) strong vapor, (2) combined vapor and melt phase and (3) thermoelastic material response. A unique quartz gauge design was utilized that employed printed circuit board (PCB) technology to facilitate electrical shielding, ruggedness, and fabrication while meeting the essential one dimensional requirements of the characterized Sandia shunted quartz gauge. Shock loading and unloading experiments were conducted to evaluate the piezoelectric response of the coupled quartz gauge/PCB transducer. High fidelity shock wave profiles were recorded at the three ion fluence levels providing dynamic material response data for vapor, melt and solid material phases.

\section{INTRODUCTION}

Development of multi-phase material constitutive models requires time resolved physical properties data i.e., stress, impulse, velocity, mass, energy, etc. Intense pulsed radiation sources, such as the GAMBLE II accelerator, located at the U. S. Naval Research Laboratory, can be used to generate material response data in solid, melt and vapor phases, which are required for model development. Due to the 10$60 \mathrm{~ns}$ GAMBLE II ion beam pulse duration, $0.5 \mathrm{Ghz}$ transducers and recording systems must be used to acquire high fidelity data. Also, the transducer and signal cable must be configured/shielded to reject electrical noise pickup/generation at accelerator discharge. Unique quartz gauges (designated AWEQG) were used in this program to acquire aluminum material response data for multi-phase states. This paper presents ion beam test results as well as quartz gauge characterization data.

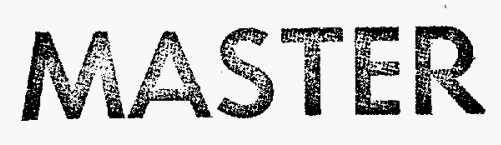

\section{QUARTZ GAUGE DESIGN AND CHARACTERIZATION}

The one-dimensional shunted $\mathrm{x}$-cut quartz gauge has been a standard for stress measurement in impact physics work since 1965 when Graham characterized its response to planar shock loading (1). This original work described the shock induced piezoelectric response of a precisely defined quartz disk (designated the Sandia Quartz Gauge (SQG) Figure 1) based on crystalographic orientation, disk dimensions, electrode configuration, guard ring width, etc. Since the original quartz characterization work, other quartz gauge configurations have been utilized in an attempt to improve certain gauge features i.e., increased signal level, longer recording time, improved electrical shielding and ruggedness $(2,3)$. Each of the changes made to the SQG design produced a deviation in the quartz piezoelectric shock response when compared to the 1965 characterization study, however.

This work was suproried by the United Siates Department of Energy under Contret DE-ACO4-94AL85000. 


\section{DISCLAMMER}

Portions of this document may be illegible in electronic image products. Images are produced from the best available original document. 
Two of the most difficult steps in producing a high quality SQG is soldering electrical leads to the thin

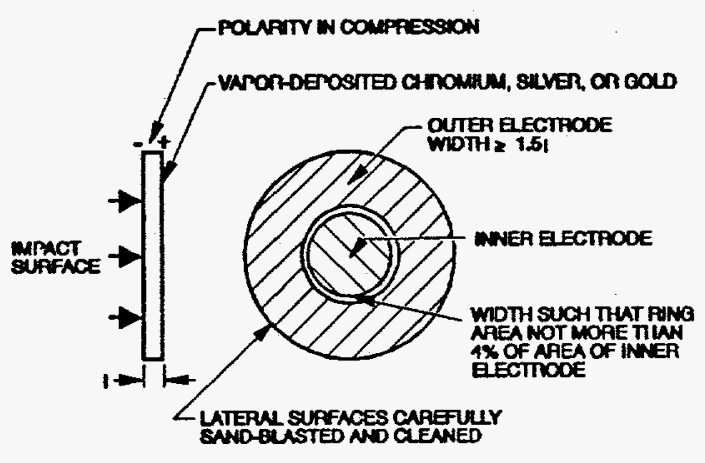

Lefracoruso

FIGURE 1. Sandia $x$-cut quartz guard-ring configuration to obtain one-dimensional conditions.

metal electrode and cutting the precise guard ring that separates the active and guard ring areas. For this ion beam application, a different approach (AWEQG) was taken to achieve both of these functions using printed circuit board (PCB) technology, in an attempt to ease fabrication and improve ruggedness. Details of the PCB technique are not presented here (patent pending). All other SQG criteria defined in Ref. 1 were adhered to in the AWEQG.

Shock loading characterization of the AWEQG configuration included gas shock tube testing and flat plate impact testing. Shock tube test results (Figure 2) confirmed overall gauge operation, with recorded gauge outputs agreeing with predicted signal levels based on Ref. 1 SQG characterization. Gauge rise time in the shock tube testing was primarily controlled by the precision of gauge-gas shock front alignment, and does not represent a gauge limitation. Shock tube test data taken before and after shipment from the UK to the US confirmed AWEQG ruggedness.

The shock tube results demostrated AWEQG response but only at low stress $(0.2 \mathrm{MPa})$. Plate impact experiments were performed to evaluate AWEQG piezoelectric response at 0.5 and $1.0 \mathrm{GPa}$ peak stress and to assess any electrical breakdown problems resulting from use of the PCB technology. Precision impact experiments were conducted using the same Sandia compressed gas gun facility used in Ref. 1. The AWEQG disk was impacted with a precisely aligned $\mathrm{x}$-cut quartz disk used as a projectile facing, whose velocity at impact was accurately measured to $\pm 0.5 \%$.

Table 1 summarizes AWEQG characterization results for three gas gun shots. Initial current jump and subsequent wave shape were evaluated for (a) long pulse loading at 0.5 and $1.0 \mathrm{GPa}$ ( 2 experiments) and (b) short pulse loading in Figure 3. The initial current jump and current at complete gauge transit were in close agreement with Ref. 1 data (Table 1). The third experiment was designed to assess the short pulse (pulse duration less than quartz gauge transit time) anomaly in shock loaded quartz (4). The anomaly, resulting from shock induced conductivity in the shocked and then unloaded quartz material, manifests
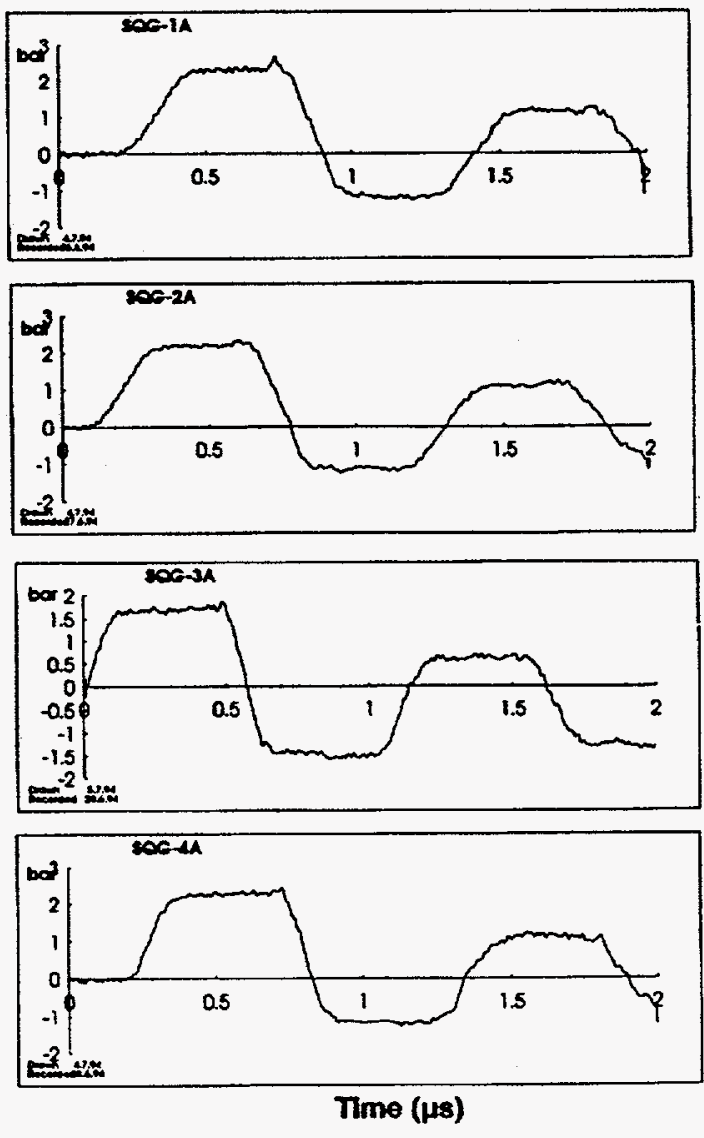

Leascordo

FIGURE 2. Representative AWEQG shock tube results (4 gauges). 
TABLE 1. AWEQG Gas Gun Experimental Results Summary.

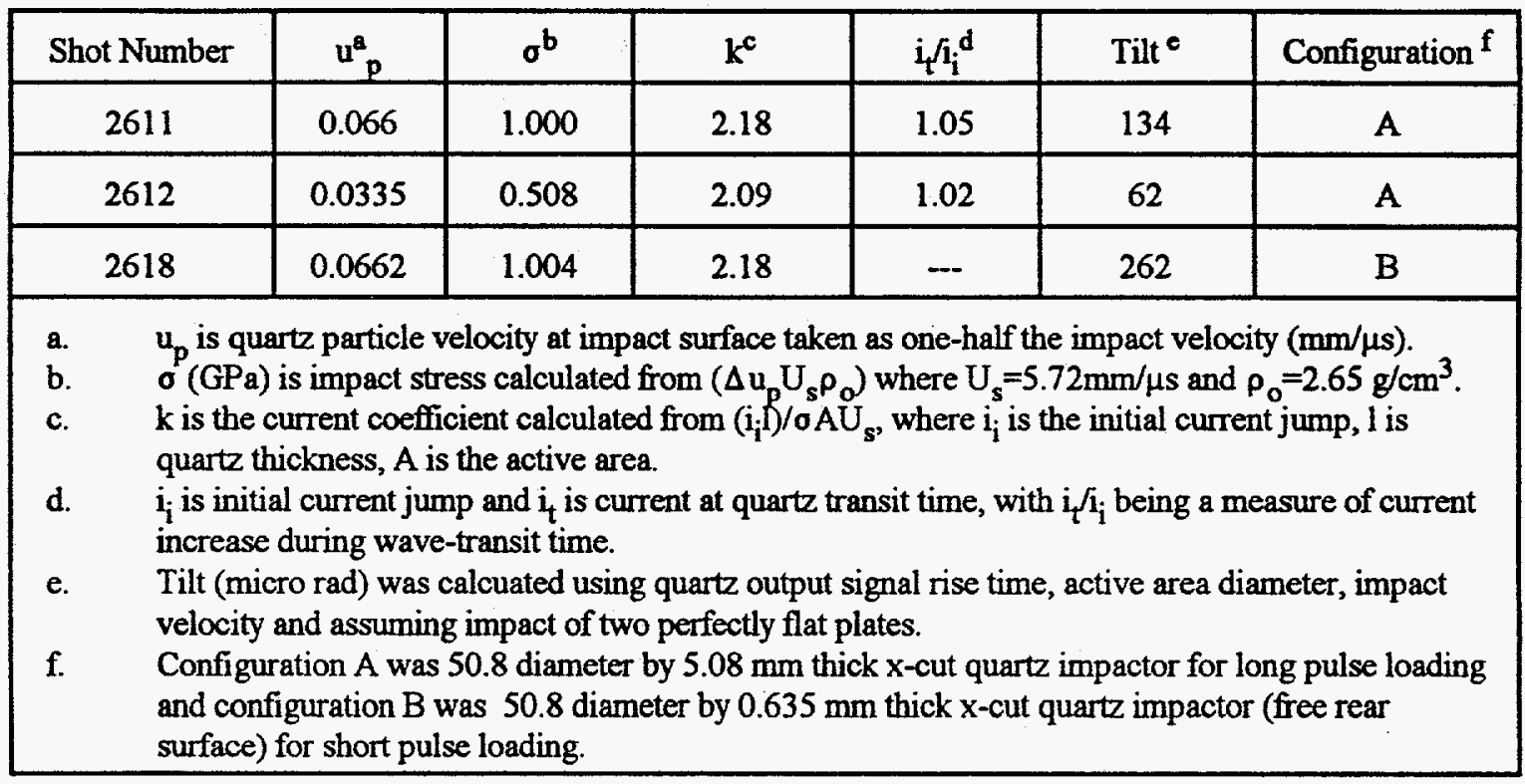

itself as an apparent charge output when there should be no output. Figure 3(b) shows the short pulse experimental data (Shot 2618) with no anomalous current output, i.e., after shock unloading the signal returns to the base line and remains there until complete transit of the gauge. Shot 2618 was designed to have normal response, based on Ref. 4 data, but was located adjacent to the normal/anomalous response boundary at $1.0 \mathrm{GPa}$. Rise time differences shown in Figure 3 were attributed to non-planarity or tilt at impact, for Shots 2611 and 2612. This high degree of planarity, a unique capability of the gun facility used, was required to define meaningful $A W E Q G$ gauge characterization data. The asymmetric rise recorded for Shot 2618 was attributed by deformation in the thin $(0.635 \mathrm{~mm})$ quart impactor due to launch loads.

\section{ION BEAM RESULTS}

The GAMBLE II accelerator produces nominally 30 $\mathrm{kJ}$ of $1 \mathrm{MeV}$ protons, producing a $50 \mathrm{~cm}$ diameter beam $1 \mathrm{~m}$ from the anode. Fluence levels can be varied from 0.1 to $100 \mathrm{cal} / \mathrm{cm}^{2}$ and are a function of distance from the anode. Ion pulse width is also dependent on distance from the anode and is between 10 and 60 ns FWHM.

Thirty one samples were irradiated in 10 ion beam experiments, with high fidelity quartz gauge data being obtained on all samples. Representative

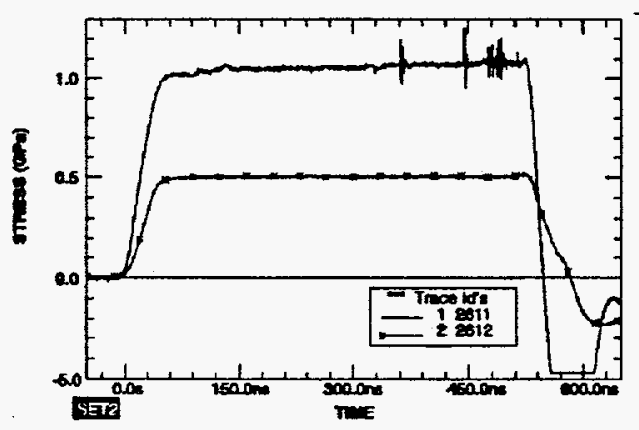

(a)

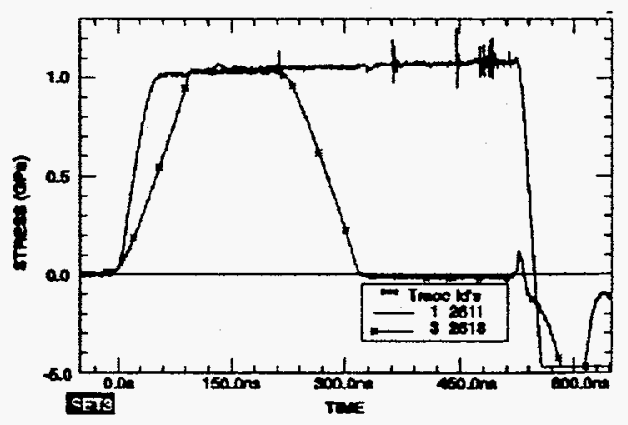

(b)

Ifroem onn

FIGURE 3. AWEQG data for (a) 0.5 and $1.0 \mathrm{GPa}$ long pulse loading and (b) $1.0 \mathrm{GPa}$ long and short pulse loading. 
AWEQG data are shown in Figure 4 for aluminum samples exposed at 15 and $1.5 \mathrm{cal} / \mathrm{cm}^{2}$. Measurable differences in stress and wave shape are apparent for the two fluence levels shown. The $15 \mathrm{cal} / \mathrm{cm}^{2}$ exposures produced fast rise shock fronts followed by gradual release representing vapor dominated response. The $1.5 \mathrm{cal} / \mathrm{cm}^{2}$ exposures, which produced thermoelastic responses, obviously generated lower peak stress with gradual rise followed by rapid stress release (compared to $15 \mathrm{cal} / \mathrm{cm}^{2}$ ). Even tensile pulses are evident for the low fluence cases showing the results of elastic wave reflections in the aluminum sample.

All AWEQG gauges were insensitive to accelerator noise generation as evidenced by the signal baseline prior to shock arrival. Also the three records at 1.5 $\mathrm{cal} / \mathrm{cm}^{2}$, which were from a single ion experiment, show close agreement in basic wave shape.

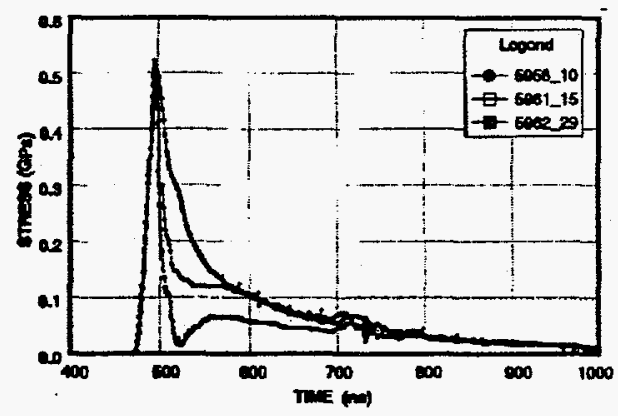

(a)

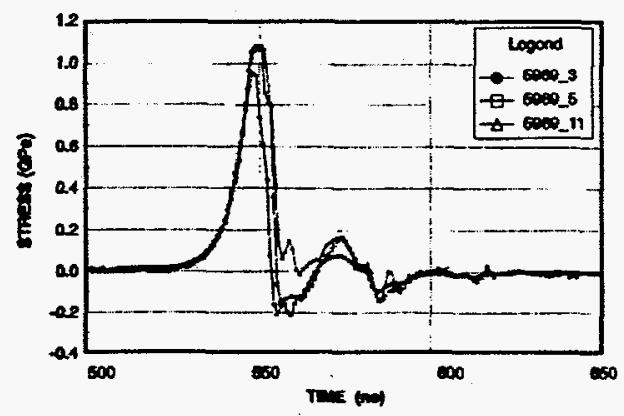

(b)

FIGURE 4. Representative AWEQG data from ion beam experiments conducted at (a) $15 \mathrm{cal} / \mathrm{cm}^{2}$ and (b) $1.5 \mathrm{cal} / \mathrm{cm}^{2}$

\section{SUMMARY}

The AWEQG stress gauges, based on SQG onedimensional criteria and employing a PCB technique, have shock induced piezoelectric characteristics (loading and unloading) identical to the SQG (Ref 1), up to $1 \mathrm{GPa}$. Also, the AWEQG did not show the anomolous current response for short pulse loading at $1 \mathrm{GPa}$. The AWEQG gauge design has excellent ruggedness and minimizes electrical noise pickup in harsh accelerator environments. In the ion beam application the quartz gauges provided high resolution stress-time data that can be used to develop multi-phase material constitutive models spanning the solid through vapor phases.

\section{REFERENCES}

1. Graham, R. A., Neilson, F. W. and W. B. Benedick, "Piezoelectric Current from Shock Loaded Quartz-A Submicrosecond Stress Gauge," J. of Applied Physics, Vol. 36, No. 5, May 1965, pp. 1775-1783.

2. Graham, R. A., "Piezoelectric Current from Shunted and Shorted Guard-Ring Quartz Gauges," SAND781911, Sandia National Laboratories, NM, December 1978, pp. 89-100.

3. Reed, R. P., "The Sandia Field Test Quartz Gage, Its Characteristics and Data Reduction," SAND 78-1911, Sandia National Laboratories, NM, December 1978 , pp. 149-176.

4. Graham, R. A., and C. E. Ingram, "Piezoelectric Current from X-Cut Quartz Subjected to ShortDuration Shock-Wave Loading," SAND 78-1911, Sandia National Laboratories, NM, December 1978, pp. $61-72$.

\section{DISCLAIMER}

This report was prepared as an account of work sponsored by an agency of the United States Goverament. Neither the United States Government nor any agency thereof, nor any of their employees, makes any warranty, express or implied, or assumes any legal liability or responsibility for the accuracy, completeness, or usefulness of any information, apparatus, product, or process disclosed, or represents that its use would not infringe privately owned rights. Reference herein to any specific commercial product, process, or service by trade name, trademark, manufacturer, or otherwise does not necessarily constitute or imply its endorsement, recommendation, or favoring by the United States Government or any agency thereof. The views and opinions of authors expressed herein do not necessarily state or reflect those of the United States Government or any agency thereof. 